\title{
Improving STEM Education for Lower-division College Students at HSI by Utilizing Relevant Sociocultural and Academic Experiences: First Year Results from ASSURE-US Project
}

\section{Dr. Jidong Huang, California State University, Fullerton}

Dr. Jidong Huang is a Professor of Electrical Engineering at California State University, Fullerton. His research had been supported by the National Science Foundation (NSF), Federal Aviation Administration (FAA) and multiple industrial sponsors. Currently, his research interests are focused on innovative approaches for STEM teaching and learning; robotics; the design of high-precision, integrated navigation system with high integrity; and their indoor/outdoor applications. He is a member of the Institute of Navigation (ION); and a senior member of the Institute of Electrical and Electronics Engineers (IEEE).

Dr. Sudarshan T Kurwadkar P.E., California State University, Fullerton

Dr. Sudarshan Kurwadkar is an Associate Professor in the Civil and Environmental Engineering Department at California State University, Fullerton (CSUF). He is a licensed Professional Engineer and a Board-Certified Environmental Engineer. During his last 10 years of teaching experience, he has received numerous awards, scholarships and fellowships. His commitment to student success is widely acknowledged with students winning many distinguished awards at various research symposiums and conferences. At CSUF, Dr. Kurwadkar is an ASCE Faculty Advisor, and recently elected Vice President of Student Affairs for ASCE Los Angeles Section. He has pursued and collaborated on many externally funded grants including NSF-CAREER, NSF-MRI, NSF-REU, NSF-IUSE, CA-DPR, IUSSTF, and US-STJF. He has secured more than $\$ 2.0$ Million in externally funded projects. Besides teaching and research, he enjoys outdoor activities such as swimming, kayaking, biking, fishing, and long-distance traveling. He has driven cross-country from Los Angeles, CA to Kittery, ME, visiting major tourist attractions all along.

\section{Dr. Doina Bein, California State University, Fullerton}

Dr. Bein has an extensive publication record: 13 book chapters, 19 journal articles, and 69 conference papers. Four of her conference papers have received the best paper awards. She was awarded (as PI or co-PI) several research and teaching grants from AFOSR and NSF. She is the general vice-chair of an annual conference, International Conference on Information Technology: New Generations (ITNG), held in April in Las Vegas, NV. She is the faculty advisor of the ACM Women in Computing (ACMW) local chapter, that organizes several outreach activities to inspire girl scouts in STEM education, and won several campus awards, Presidential Award from the Girl Scouts of America, and the 2018 Inspiring Programs in STEM Award from INSIGHT Into Diversity magazine.

Dr. Yu Bai, California State University, Fullerton

Dr. Yu Bai is an Assistant Professor in the Computer Engineering Program in the College of Engineering and Computer Science at the California State University, Fullerton. His research has been supported by Intel and other federal agencies. His research interests include machine learning, social media analysis, neuromorphic computing, FPGA design, nano-scale computing system with novel silicon and post-silicon devices, and low power digital and mixed-signal CMOS circuit design.

Dr. Salvador Mayoral, California State University, Fullerton

Dr. Salvador Mayoral received his Ph.D. in Mechanical and Aerospace Engineering from the University of California, Irvine in 2013. As a graduate student, Dr. Mayoral worked on the shielding of jet noise by a hybrid wing body aircraft. In 2014, Dr. Mayoral joined the Department of Mechanical Engineering at California State University, Fullerton where he currently serves as an Assistant Professor. As the PI of the Wind Tunnel Laboratory, his research interests span the areas of aeroacoustics, ground effect aerodynamics, and has recently expanded his interests into the hydrodynamics of marine life. Moreover, Dr. Mayoral is a CoPI of the NSF funded "Advancing Student Success by Utilizing Relevant Social-cultural and Academic Experiences for Undergraduate Engineering, Computer Science Students" (ASSURE-US) Project. 


\title{
Improving STEM Education for Lower-division College Students at HSI by Utilizing Relevant Sociocultural and Academic Experiences: First Year Results from ASSURE-US Project
}

\author{
Jidong Huang ${ }^{1}$, Sudarshan Kurwadkar ${ }^{2}$, Doina Bein ${ }^{3}$, Yu Bai ${ }^{4}$, Salvador Mayoral $^{5}$ \\ ${ }^{1}$ Department of Electrical Engineering \\ ${ }^{2}$ Department of Civil and Environmental Engineering \\ ${ }^{3}$ Department of Computer Science \\ ${ }^{4}$ Computer Engineering Program \\ ${ }^{5}$ Department of Mechanical Engineering \\ California State University, Fullerton, Fullerton, CA, USA \\ *Corresponding author: skurwadkar@fullerton.edu
}

\begin{abstract}
Despite national efforts in increasing representation of minority students in STEM disciplines, disparities prevail. Hispanics account for $17.4 \%$ of the U.S. population, and nearly $20 \%$ of the youth population (21 years and below) in the U.S. is Hispanic, yet they account for just 7\% of the STEM workforce. To tackle these challenges, the National Science Foundation (NSF) has granted a 5-year project - ASSURE-US, that seeks to improve undergraduate education in Engineering and Computer Science (ECS) at California State University, Fullerton. The project seeks to advance student success during the first two years of college for ECS students. Towards that goal, the project incorporates a very diverse set of approaches, such as socio-cultural and academic interventions. Multiple strategies including developing early intervention strategies in gateway STEM courses, creating a nurturing faculty-student interaction and collaborative learning environment, providing relevant, contextual-based learning experiences, integrating project-based learning with engineering design in lower-division courses, exposing lower-division students to research to sustain student interests, and helping students develop career-readiness skills. The project also seeks to develop an understanding of the personal, social, cognitive, and contextual factors contributing to student persistence in STEM learning that can be used by STEM faculty to improve their pedagogical and studentinteraction approaches. This paper summarizes the major approaches the ASSURE-US project plans to implement to reduce the achievement gap and motivate ECS students to remain in the program. Preliminary findings from the first-year implementation of the project including preand post- data were collected and analyzed from about one hundred freshmen and sophomore ECS students regarding their academic experience in lower-division classes and their feedback for various social support events held by the ASSURE-US project during the academic year 2018-19. The preliminary results obtained during the first year of ASSURE-US project suggests that among the different ASSURE-US activities implemented in the first year, both the informal faculty-student interactions and summer research experiences helped students commit more to
\end{abstract}


their major during their lower-division years. The pre-post surveys also show improvements in terms of awareness among ASSURE-US students for obtaining academic support services, understanding career options and pathways, and obtaining personal counseling services.

\section{Introduction}

Billions of dollars are allocated every year to fund research, program development, and direct services aimed at increasing the number of underrepresented populations including women and minorities entering the STEM major/career pipeline. Nevertheless, disparities in STEM representation of the Hispanic community prevail. Hispanics account for $17.4 \%$ of the US population, and nearly $20 \%$ of the youth population (21 years and below) is Hispanic, yet they account for just 7\% of the US STEM workforce. Ensuring America's global competitive edge in science and technology is contingent upon a steady supply of skilled workers in STEM disciplines. According to the President's Council of Advisors on Science and Technology (PCAST, 2012), the growth of the Hispanic student population has a unique advantage to fill this critical gap in the STEM workforce by increasing their retention in STEM disciplines.

However, narrowing the achievement gap requires careful consideration of underlying causes of unequal participation in STEM disciplines that affect underrepresented minorities (URM) students, including Hispanics and females. For URM students, often a combination of ethnicity, gender, sociocultural influences, academic experiences and preparation, cognitive, attitude/perceptions, institutional variables, and environmental factors affect not only their choice of majors but also their ability to perform and succeed in their chosen major (Coulombe and Gil, 2016; Crisp and Nora, 2012). This disparity between the URM and non-URM students is also reflected in their overall participation in the STEM workforce. In mid-1980, the Engineering Deans' Council reported that across the US, on average, nearly $40 \%$ of students leave engineering before graduation. This rate is much higher for URM and female engineering students with $70 \%, 70 \%$, and $50 \%$ of female, black and Hispanic students respectively. It is not surprising that there is a disproportionate representation of the overall URM population and their representation in the STEM workforce (Figure 1).

As shown in Figure 1, Hispanics and Blacks account for approx. 15\% and $12 \%$ of the US residential population 21 years or older in 2015, yet they account for only $6 \%$ and $5 \%$ of the science and engineering occupation (National Science Board, 2018). 


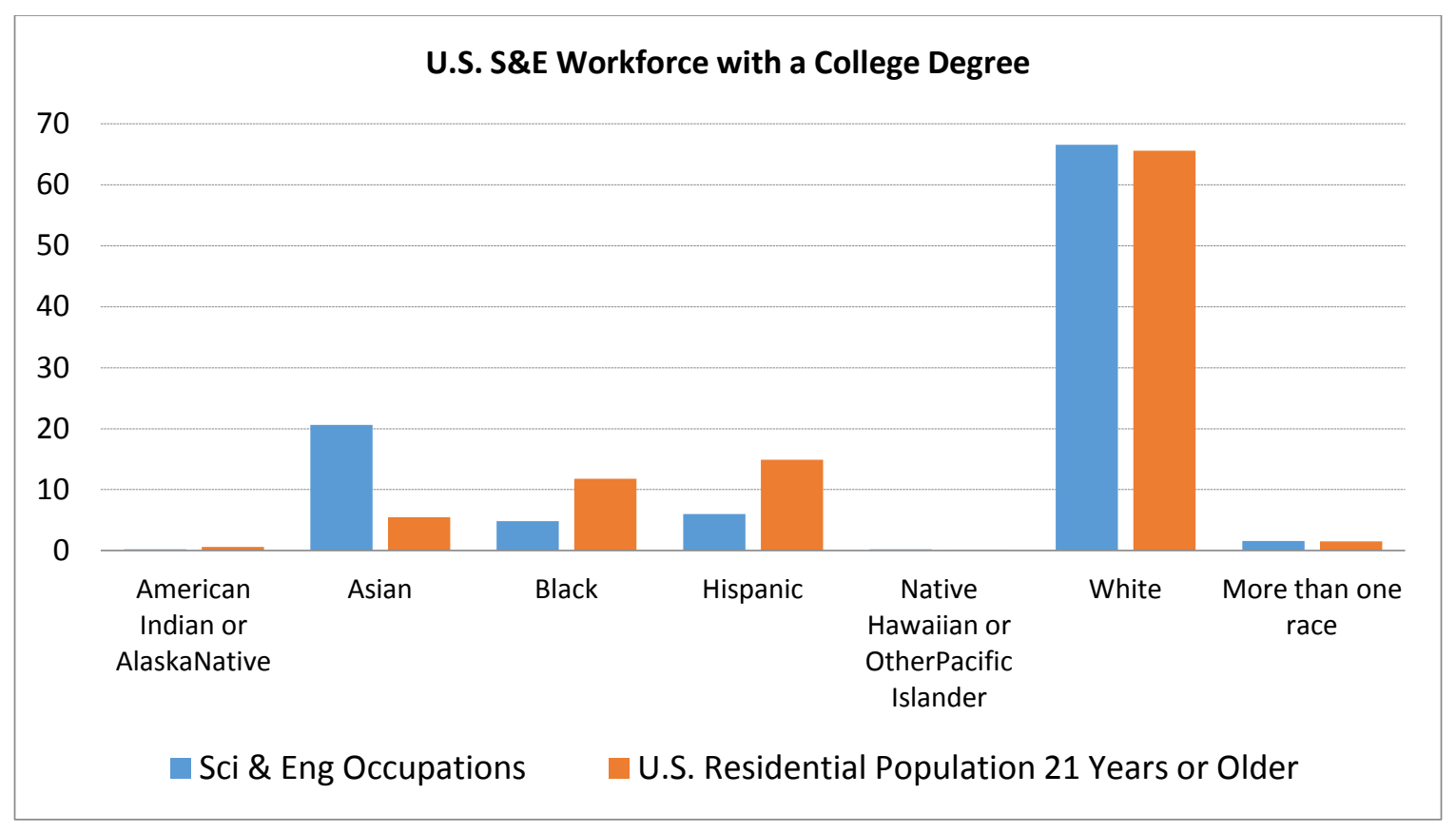

Figure 1. The ethnic and racial distribution of Sci. \& Eng. workforce with a college degree, 2015 (Source: Science and Engineering Indicators, 2018)

Given that Hispanic-Serving Institutions (HSI) are the colleges and universities where most of the country's Hispanic college students graduate from, it is critical to improve undergraduate STEM education at HSI by providing URM students proportionate and equitable opportunities.

California State University, Fullerton (CSUF) is an HSI serving over 40,000 students, of which $65 \%$ are from ethnic minority groups, and nearly one-third are first-generation college students. It is a leading institution in California and the nation in preparing its diverse student body for academic and professional success. Nevertheless, STEM programs at CSUF, such as Engineering and Computer Science (ECS) programs continue to face a multitude of challenges in reducing the high repetition rate in lower-division gateway courses, lowering the achievement gap, and improving the graduation rates for underrepresented groups.

When the academic performance of URM students was compared against the non-URM students across all the ECS disciplines, there generally exists an achievement gap. For example, data analyzed from 2001-2017 clearly shows the average repetition rate for URM students is generally higher than their non-URM counterparts, particularly in lower-division math and science courses (Figure 2, a). As shown in Figure 2, this achievement gap is pervasive throughout all the disciplines in the ECS, not only in lower-division ECS courses but also across some upper-division ECS courses. Given that course repetition is a good indicator of student success and retention, it clearly shows there are achievement gaps between URM students and their non-URM peers, which starts early on in lower-division math and science courses as these courses build the foundation for upper-division ECS courses. 

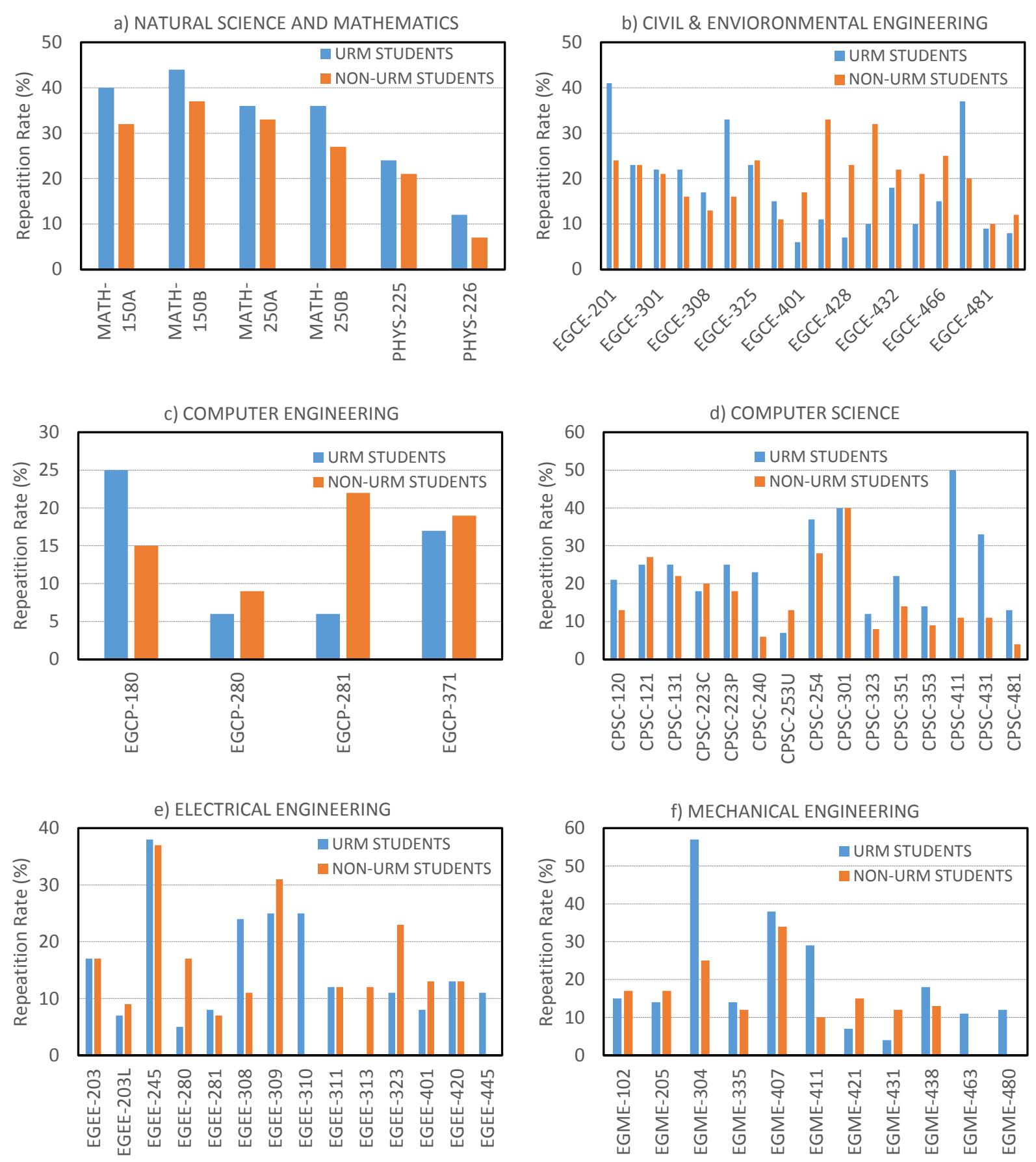

Figure 2. The achievement gap between URM and non-URM students in all ECS disciplines. The performance demonstrates a perpetuation of the achievement gap in lower-division math and science courses that continued in their senior years.

The net result of this achievement gap is a delayed graduation rate. Figure 3 shows the 4-, 5- and 6-year graduation rates for URM and non-URM ECS students at CSUF. It appears that there is an upward trend over the years in the graduation rate of both URM and non-URM 
students. However, the graduation rate of URM students still lags the graduation rates of general student peers.

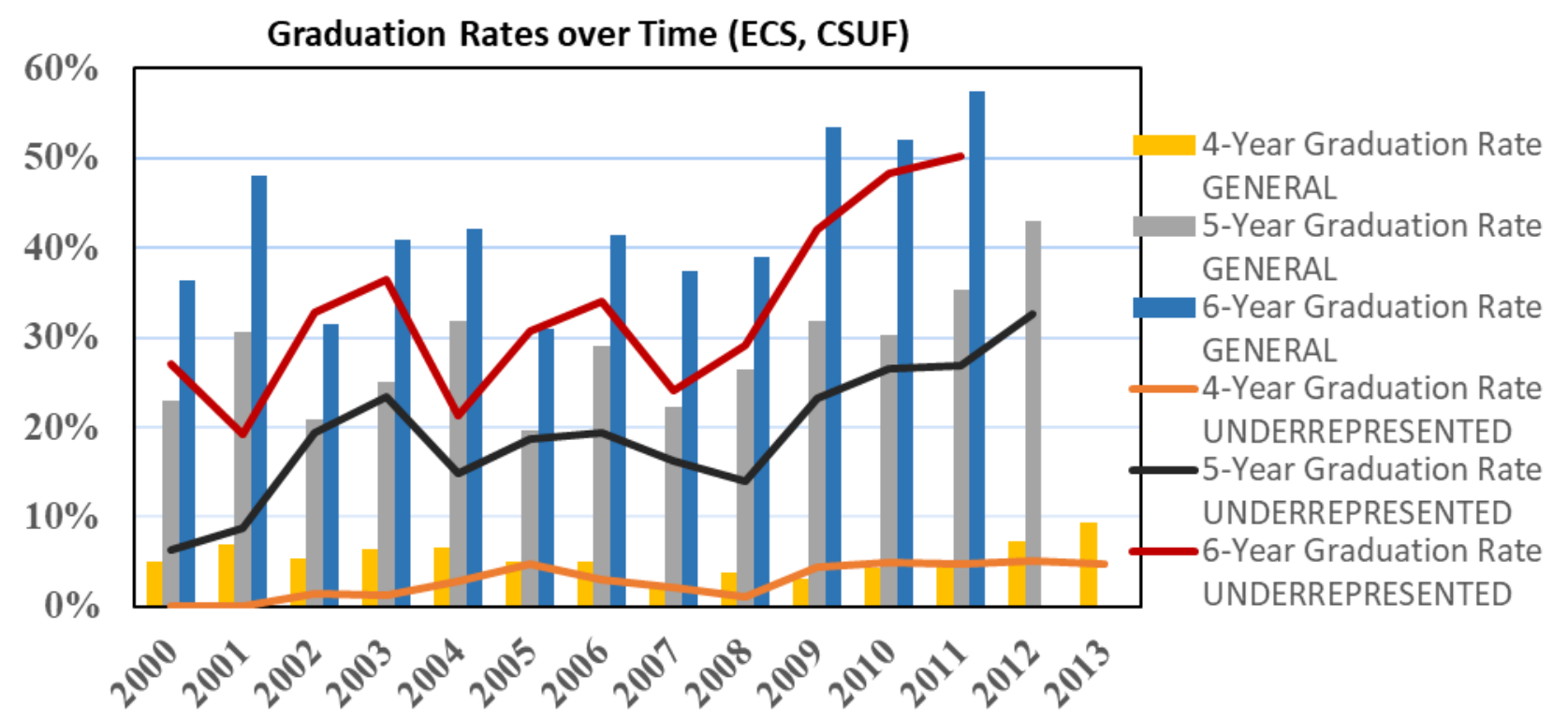

Figure 3. The perpetuation of achievement gap reflected in the overall graduation rate of URM and general students between 2000 and 2013

Consistent with the literature (Kane et al., 2004; Horwitz and Ebrahimpour, 2002), the ASSURE-US project was designed to tackle these challenges in the early lower-division courses, with the overarching goal to improve undergraduate education in ECS to advance student success at critical transitions. Therefore, the project integrates mixed methods using both quantitative and qualitative approaches to answer the following research questions:

1. Do informal faculty interactions, advising through social media, family, and community engagement have a positive impact on URM student persistence in STEM education at HSI?

2. Does integrating contextual-based learning targeted explicitly towards bottleneck Math and ECS courses improve success for URM students?

3. Will early intervention through the targeted approach in gateway courses with high repetition rates promote timely completion and increase the morale of URM students?

4. Does first and second-year student involvement in faculty-directed, field-based research experience have a positive effect on retaining undergraduate students pursuing STEM majors?

\section{ASSURE-US Program Design}

As mentioned above, the ASSURE-US goals are geared towards creating an integrated, sustainable support system comprising of both academic and socio-cultural intervention 
strategies. Besides these intervention strategies, concerted efforts were made to provide holistic learning experiences to students through targeted engagement in project design and research activities in lower-division levels.

Summarized below are some critical elements implemented by the ASSURE-US project during its first year. Please note that in the first year, the project did not implement any academic intervention strategies in lower-division bottleneck courses due to the paucity of time in identifying target courses, developing intervention plans, and providing faculty development.

\section{Student-Teacher Interaction Council (STIC)}

Consistent with the literature (Lisagor et al., 2013; Concepción et al., 2009), the formation of the STIC is to build rapport with students, facilitate informal communication between students and faculty, present role models to emulate and seek inspiration from, educate students about campus resources and opportunities available for success, and keep motivation and enthusiasm levels high so that they remain engaged in their academic pursuits.

In year one, ASSURE-US planned and executed a variety of STIC meetings, including off-campus faculty-student social gathering, lab tours, campus resource, and financial planning workshop, stress managing, and exam preparation workshop, and industry field trip. Additionally, student family members were invited to participate in lab tours and the summer research experience poster presentations.

\section{Advising and Learning Community}

A longitudinal study by Dennehy \& Dasgupta (2017) showed that informal mentorship, especially mentoring from the peer of similar background, could alleviate anxiety about engineering and promote aspiration to pursue engineering careers by providing a sense of belonging and confidence. Accordingly, ASSURE-US hired six peer mentors in its first year across all ECS majors and used these peer mentors to provide advising and support to ASSUREUS student participants.

\section{Faculty Development and Support}

A key contributing factor for the overachieving goal in ASSURE-US is to promote faculty's development, which potentially improves their pedagogical skills, helps enhance

curriculum content, and facilitates understanding of student needs. In ASSURE-US, faculty development and support were targeted towards the lower division gateway courses in ECS, Science, and Mathematics. The training was focused on course module development for lowerdivision Engineering, Mathematics, and Science courses to incorporate high impact practices.

\section{Undergraduate Research for Freshman and Sophomore Students}

Undergraduate research consisting of laboratory/field activities and design projects involving students, peer mentors, and faculty members were implemented in the Summer of 
2019. These activities were intended to increase the persistence of URM students in STEM disciplines. The objective of Summer Undergraduate Research Experiences (SURE) was to increase students' comprehension of concepts and topics and develop skills through real-world experiences at a very early stage as a freshman or sophomore.

\section{ASSURE-US Student Participants}

In the academic year 2018-19, students were recruited to ASSURE-US through a variety of means, including email invitations, classroom presentations, and program introduction during the freshman orientation, and recruitment flyers posted throughout the ECS. As a result, 154 students applied to join ASSURE-US, of which nearly 134 students participated in various ASSURE-US project activities, and 76 consented to join the ASSURE-US research study.

The ASSURE-US project examined the background of its student participants to target intervention strategies to help URM students in ECS specifically.

Figure 4 shows the composition of ASSURE-US students from different majors. The project has impacted students from all ECS majors. Interestingly, students from computer-related majors such as computer science and engineering, were more willing to take part in the ASSURE-US activities.

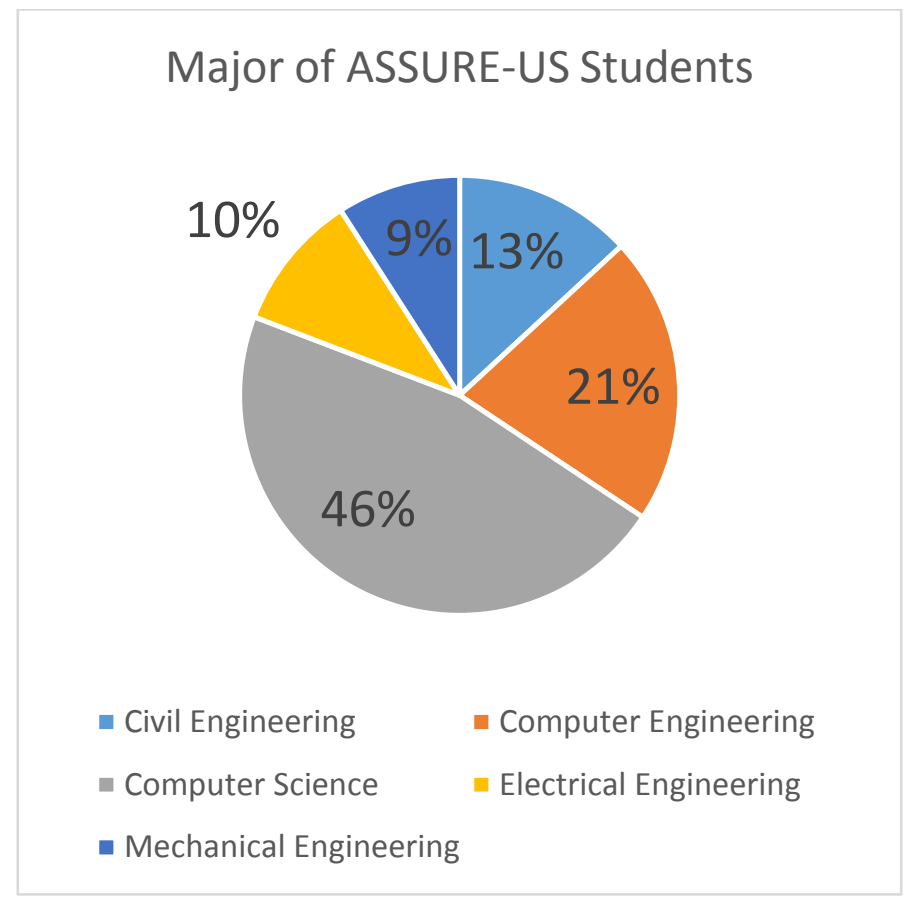

Figure 4. Composition of students representing various engineering majors who participated in the ASSURE-US project activities. 
Since the project seeks to investigate how factors other than academic preparation have overall implications for student perseverance in ECS majors, a variety of data such as gender, non-academic commitment, and economic background were also collected. The gender composition of ASSURE-US students suggests that more male students at $67 \%$ participated in the ASSURE-US project activities compared to female students at 33\%.

Shown in Figure 5 is the academic status of ASSURE-US students. During the first year, many freshman students participated in the ASSURE-US project activities compared to sophomore students.

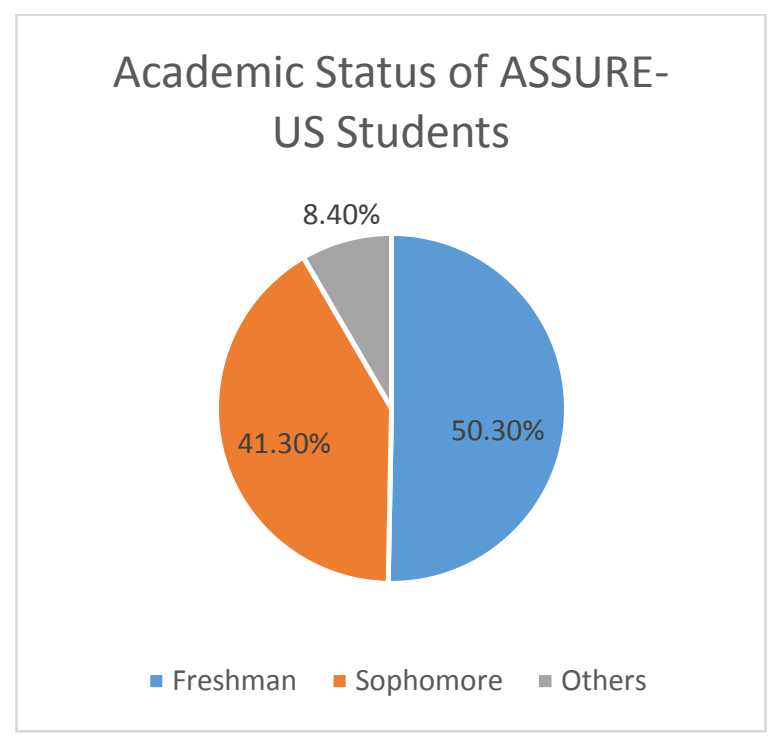

Figure 5. Academic status of students participating in the ASSURE-US project activities.

The project also investigated student commitments other than academics. Figure 6 shows the percentage of students and the number of hours they need to work while they attend college at CSUF. The severity of economic pull factors is so grave that, even at the freshman and sophomore level, almost half of the ASSURE-US students were engaged in part-time work to support themselves.

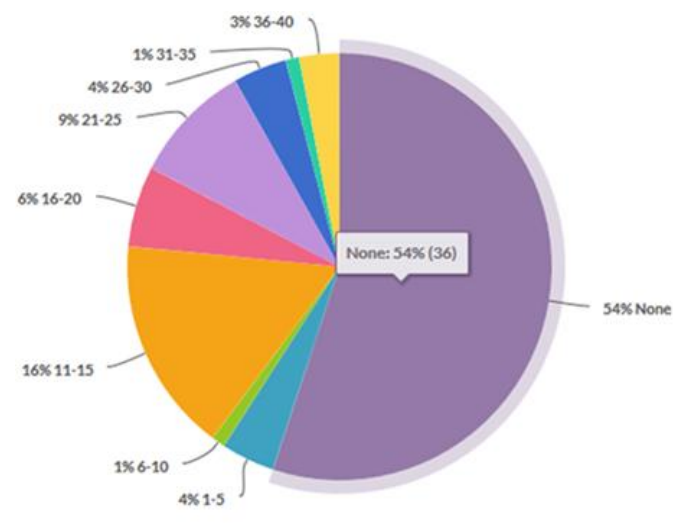

Figure 6. Number of part-time work hours for ASSURE-US students. 
Figure 7 shows if a student has additional family obligations, such as babysitting, while they attend college. It appears that most of the ASSURE-US students have some family obligations while they attend college.

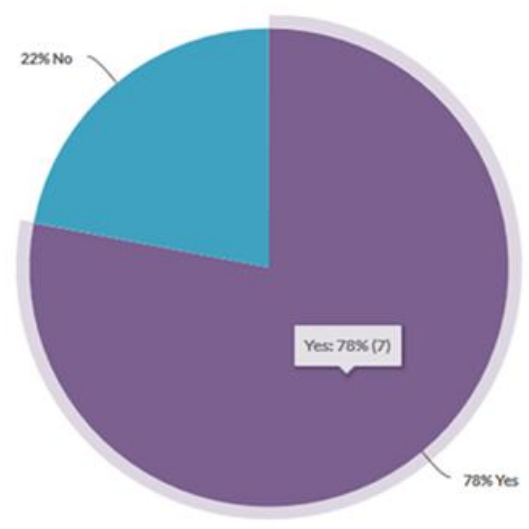

Figure 7. Family obligation for ASSURE-US students.

When it comes to financial support, as shown in Figure 8, most ASSURE-US students received some type of grants to support their studies.

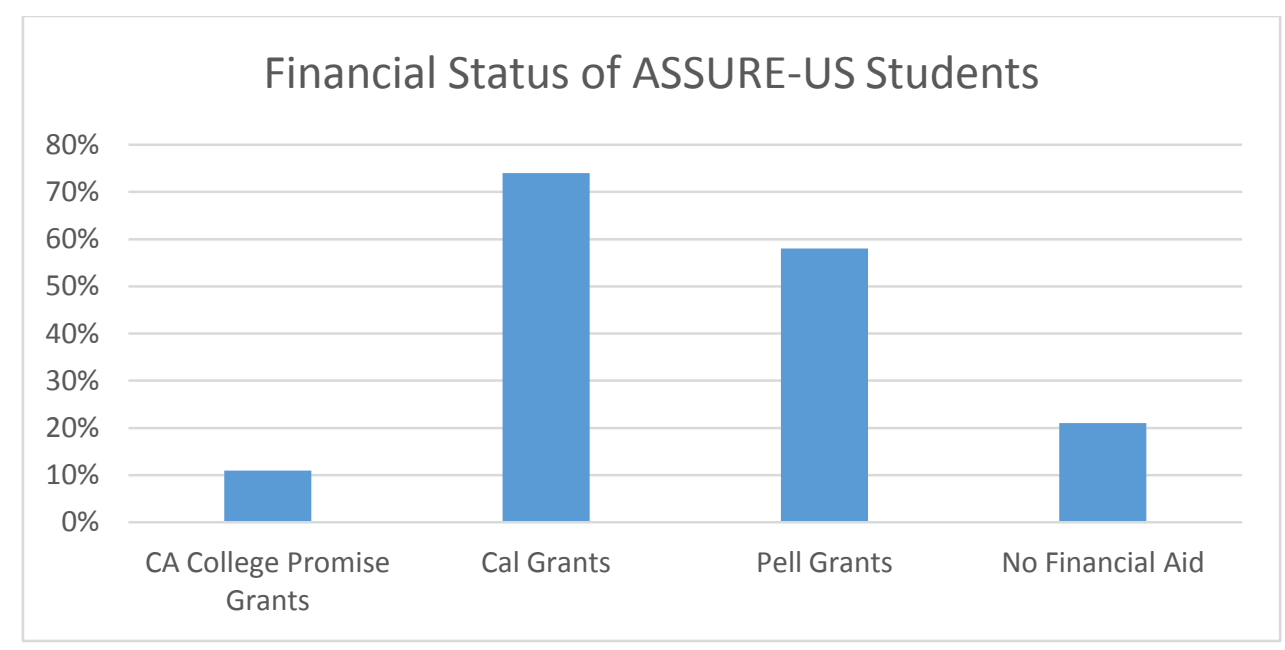

Figure 8. Need-based grants received by ASSURE-US students.

\section{Project Evaluation and Research}

Arroyo Research Services (ARS) conducted the ASSURE-US external evaluation and collaborated on the ASSURE-US research study. The external evaluation was intended to complement and support both the programmatic and research aspects of ASSURE-US. The primary evaluation goals include: 1) monitoring the development, implementation, and 
documenting the progress of project's various aspects (e.g., recruitment, learning module development, professional development, STIC implementation, family engagement, peer mentoring and faculty development) and monitoring research study execution (data collection, research design implementation, data analysis), and 2) determining and reporting the effectiveness of the project and research study in reaching its intended aims.

The ASSURE-US evaluation instruments were built from psychometrically sound instruments and scales. For instance, the Career Interest Questionnaire and Modified STEM Semantics Survey (Tyler-Wood et al., 2010) and the Student Attitudes toward Science Survey (Gibson and Chase, 2002) were used to measure student fascination, value and competency beliefs with STEM education and careers.

Specifically, the process evaluation of the project was designed to measure both quality and intensity of ASSURE-US activities to monitor the short-term and formative results of activities and services, validate program components and determine whether activities were of sufficient quality and intensity to influence intended outcomes. Example questions for the formative evaluation include "Were strategic recruitment strategies designed and implemented to recruit URM student participants?" and "To what extent do students participate in mentoring, informal events, family and community engagement efforts, and learning communities/advising?". To answer these questions, process data were collected through project documents, post-event participant surveys, attendance logs, and a focus group with observations and interviews.

The summative evaluation of the project focuses on assessing the research questions of the project to evaluate if the program reaches its intended outcomes; and how the different intervention strategies in the project impact student learning. Example questions for the summative evaluation include "Did the overall repetition and passing rates in ASSURE-US identified gateway courses improve for URM students and all students after implementing academic interventions in those gateway courses?" and "Which ASSURE-US program activities were the most effective? Which components require improvement?" To answer these questions, pre-/post- surveys on student persistence in STEM majors and gateway course outcomes (grades, repetition, and failure rate) were collected.

\section{Preliminary Results}

The ASSURE-US project implementation started immediately upon funding and was implemented in good faith and speed, with typical year-one project adjustments and learning for a brand-new initiative. ASSURE-US planned and executed 11 Student-Teacher Interaction Council (STIC) and informal events throughout Year One, as planned, beginning with an offcampus kickoff meeting in October that attracted 43 students and 12 faculty and staff. STIC outcomes include measures embedded in the overall study design, as well as STIC-specific 
surveys and items administered after the initial STIC events. Initial STIC event surveys show results of participating in STIC events; students agreed or strongly agreed as follows:

- $89 \%$ met people they didn't know

- $97 \%$ felt welcome

- $64 \%$ had meaningful interactions with faculty

- $67 \%$ feel more connected to faculty in their program

- $83 \%$ feel more connected to students in their program

Regarding student awareness and engagement, ASSURE-US students reported pre to post change in the areas shown below in Tables 1 and 2, based on Pre-Surveys administered in September 2018 and Post-Surveys administered in June 2019.

Table 1. Pre-Post Student Awareness of Resources and Pathways

\begin{tabular}{|c|c|c|c|}
\hline & $\begin{array}{c}\% \text { Fully } \\
\text { Aware } \\
\text { Pre }\end{array}$ & $\begin{array}{c}\% \text { Fully } \\
\text { Aware } \\
\text { Post }\end{array}$ & Item \\
\hline$\uparrow$ & 46 & 50 & Obtaining academic support for important courses in my major \\
\hline$\downarrow$ & 71 & 63 & Understanding what courses to take and in what order for my major \\
\hline$\downarrow$ & 47 & 44 & Mastering core content in my major \\
\hline$\uparrow$ & 22 & 38 & Understanding career options and pathways \\
\hline$\uparrow$ & 34 & 52 & Obtaining personal counseling or other mental health services \\
\hline
\end{tabular}

Note: Response options were Not Aware, Somewhat Aware, and Fully Aware.

Table 2. Pre-Post Student Engagement

\begin{tabular}{|lccl|}
$\begin{array}{c}\text { \% Agree } \\
\text { Pre }\end{array}$ & $\begin{array}{c}\text { \% Agree } \\
\text { Post }\end{array}$ & Item \\
\hline$\uparrow$ & 73 & 77 & I look forward to my courses \\
\hline- & 72 & 71 & I enjoy engaging with classmates \\
\hline- & 68 & 69 & I enjoy engaging with my professors \\
\hline$\downarrow$ & 78 & 71 & I am happy to spend time on campus \\
\hline- & 85 & 83 & My university experiences are helping me learn and grow \\
\hline
\end{tabular}

Note: Response options were Strongly disagree, Disagree, Neither agree nor disagree, Agree, Strongly agree. 
It is worth noting that participating in the ASSURE-US project helped improve student awareness and engagement in some areas, but there are still other areas that could be improved. Additionally, while these changes may be associated with program participation, many other factors, including the full year of college and course experience, affected how students respond to the survey questions. Future analyses will examine these outcomes by level of ASSURE-US participation as well.

Additionally, in its first year, ASSURE-US supported 21 freshman and sophomore student interns across five faculty mentors in 2019 Summer Research Experiences. Students received a stipend to assist ASSURE-US leadership team members in conducting research projects, such as "Real-Time Object Detection using Artificial Intelligence" and "Self-driving Lego Robot using Artificial Intelligence." Students who participated in the SURE had the longest and strongest ASSURE-US program experience, and as shown in the initial results. Representative responses from SURE participants about what they gained from experience include, "I learned what my passion is" and "I learned Python and how to navigate Linux operating systems.” Key reported outcomes from SURE are:

- $79 \%$ believe that they contributed something of value to the project

- $92 \%$ report that their role involved doing real science, technology, engineering, or mathematics

- $79 \%$ report being more committed to their major as a result of SRE

- $86 \%$ report having a better understanding of what professionals in their field of study do as a result of SURE

In conclusion, activities conducted over one year has: a) established the baseline for course changes and faculty professional development, b) established the baseline for student knowledge and engagement, and c) provided preliminary outcomes related to Year One program elements.

\section{Discussions}

As demonstrated by the preliminary results, the year one data gathering and analysis from the ASSURE-US project a) established a baseline for student knowledge and engagement, and $b$ ) provided preliminary outcomes related to Year One program elements.

In the preliminary results, students reported high satisfaction with the STIC events for helping them to connect more with their peers and faculty. There are also improvements to student awareness and engagement in some of the areas studied, particularly for obtaining academic support, understanding career options and pathways, and obtaining personal counseling services. And the summer research experience significantly impacted the freshman and sophomore student participants and helped them to be more committed to their major. 
However, due to the short time of implementation, these preliminary results were not able to tell which program component contributed to student success, and if there are any, how much contribution it brings. In the future, the project will continue to collect data to study how different project activities in ASSURE-US correlates to student success, especially for URM students.

\section{Acknowledgments}

The research presented in this paper was supported by an HSI grant from the National Science Foundation (Grant number DUE-1832536). The authors would like to thank all project staff, student assistants, and peer mentors. The authors would like to acknowledge project evaluator Mr. Kirk Vandelrsall from Arroyo Research Services, and data support from the CSUF Institutional Effectiveness office for their contributions to this research.

\section{References}

1. Concepción, D., Holtzman, M., and Ranieri, P. (2009). Sustaining student and faculty success: A model for student learning and faculty development. International Journal for the Scholarship of Teaching and Learning, 3(1), 1-10. https://doi.org/10.20429/ijsotl.2009.030129

2. Coulombe, K., Gil, W. R. (2016). The Changing U. S. Workforce: The Growing Hispanic Demographic and Workplace. A report prepared by the Society for Human Resource Management (SHRM) and the Congressional Hispanic Caucus Institute. Retrieved from the Society for Human Resource Management Website: https://www.shrm.org/hr-today/public-policy/hr-publicpolicy-issues/Documents/15-0746\%20CHCI_Research_Report_FNL.pdf

3. Crisp, G., and Nora A. (2012). Overview of Hispanics in Science, Mathematics, Engineering, and Technology (STEM): K-16 Representation, Preparation, and Participation. White paper prepared for the Hispanic Association of Colleges and Universities. Retrieved from the Hispanic Association of Colleges and Universities Website: https://www.hacu.net/images/hacu/OPAI/H3ERC/2012_papers/Crisp\%20nora\%20\%20hispanics $\% 20$ in $\% 20$ stem\%20-\%20updated\%202012.pdf

4. Engineering Deans' Council, Findings and Recommendations from the Report of the Task Force on the Engineering Student Pipeline, Engineering Education, May 1988, pp. 778-781.

5. Gibson, H.L., and Chase, C. (2002) Longitudinal Impact of an Inquiry-Based Science Program on Middle School Students' Attitudes toward Science. Science Education, 86, 693-705.

6. Horwitz, A., and Ebrahimpour, A. (2002). Engineering Applications in Differential and Integral Calculus. International Journal of Engineering Education. 12(1). 78-88.

7. Kane, M. A., Beals, C., Valeau, E. J., Johnson, M. J. (2004). Fostering Success among Traditionally Underrepresented Student Groups: Hartnell College's Approach to Implementation of the Math, Engineering, and Science Achievement (MESA) Program, Community College Journal of Research and Practice, 28(1), 17-26, DOI: 10.1080/10668920490251944

8. Knight, D. W., Carlson, L. E., Sullivan, J. F. (2003). Staying in Engineering: Impact of a HandsOn, Team-Based, First-Year Projects Course on Student Retention. Proceedings of the 2003 American Society for Engineering Education Annual Conference \& Exposition, Copyright $\odot$ 2003, American Society for Engineering Education 
9. Lisagor, T., Augustin, F., Lucero-Liu, A., and Efrat, R. (2013). Using Faculty Learning Communities to Improve Latino Student Success. Learning Communities Journal, 5, 73-96.

10. National Science Board. 2018. Science and Engineering Indicators 2018. NSB-2018-1. Alexandria, VA: National Science Foundation. Available at https://www.nsf.gov/statistics/indicators/.

11. PCAST (2012). President's Council of Advisors on Science and Technology. Report to the president: Engage to Excel: Producing one million additional college graduates with degrees in science, technology, engineering, and mathematics. Washington, DC: Executive Office of the President. Retrieved March 4, 2018, from https://obamawhitehouse.archives.gov/sites/default/files/microsites/ostp/pcast-engage-to-excelfinal_2-25-12.pdf

12. Tyler-Wood, Tandra \& Knezek, Gerald \& Christensen, Rhonda. (2010). Instruments for Assessing Interest in STEM Content and Careers. Journal of Technology and Teacher Education. 18. 